\title{
LVIII. On pyroligneous æther
}

\section{Philip Taylor}

To cite this article: Philip Taylor (1822) LVIII. On pyroligneous æther, Philosophical Magazine Series 1, 60:294, 315-317, DOI: 10.1080/14786442208652845

To link to this article: http://dx.doi.org/10.1080/14786442208652845

$$
\text { 曲 Published online: } 29 \text { Jul } 2009 .
$$

Submit your article to this journal 전

Q View related articles 두 
purpose : which latter, however, renders the observation of the entrance of a star very uncertain and troublesome."

" M. Frauenhofer conceived the fortunate idea of placing, in the focus of the telescope, a glass pierced in the centre with a hole sufficient to admit of a metal ring, which was attached thereto, and which ring was then turned perfectly circular: and, as it was never afterwards separated from the glass, its circulior form remained uninjured."

"The great advantage attending this method is that the metal circle requires no other support, since the glass itself is fixed to the diaphragm: and thus the double concentric circle (which forms the micrometer) seems to hang without support in the expanse of the heavens."

[Our mathematical instrument-makers occasionally construct the micrometer of a transit instrument by means of fine lines drawn with a diamond on glass : and I conceive it would not be more difficult to draw tro concentric circles in the same manner; which would probably answer every purpose to which the circular micrometer is usually applied. There appears to be only one objection to this plan : which is, that the loss of light (which however is not great) may prevent the observation of small comets, and very minute stars ; to which class of objects the circular micrometer is peculiarly adapted.-F. B.]

LVIII. On Pyroligneous Ather. By Philip Tayıon.

\section{To the Editors of the Philosophical Magazine and Journal.}

Gevtumen,-Ix the Philosophical Magazine for August last, I observed the following extract from one of the foreign journals ${ }^{*}$ :

" On examining different samples of pyroligneous acid, $\mathbf{M}$. Dobereiner lately found alcohol in two of them obtained from birch-wood."

As I believe there is an error in this statement, I shall trouble you at this time with a few remarks upon it, and in a future number of the Magazine detail more fully the experiments which have led me to the conclusions I have formed on this subject.

The peculiar fluid which M. Döbereiner calls alcohol was first discovered by me in the year 1812; at which time I was extensively engaged in the manufacture of pyroligneous acid and the various preparations formed with it. In attempting to purify this acid by a new process, I observed that both the colouring matter and that which gives it its characteristic odour

$$
\text { * Schweigrger's N. J"t. fuir Chem. u. Phys. }
$$


were held in solution chiefly by a very volatile and inflammable fluid. Having separated some of this peculiar fluid from the acid, and deprived it of its colouring matter by repeated rectifications, I was struck with its strong resemblance to alcohol in many of its characters.

I found it perfectly miscible with water:-that it dissolved camphor and all the gum resins quite as readily and as abundantly as alcohol does; that it burned with a flame like that of alcohol; and that its specific gravity varied from 830 to 900 , according to the care taken in its rectification.

As I had convinced myself that this spirit might be obtained in considerable quantity, and would be useful for various processes in the arts, I was naturally led to think how far its similarity to spirits of wine might subject it to the excise laws; and I made a series of experiments to ascertain if it could truly be called alcohol.

Many of these experiments were rather interesting; but I will at this time only mention one, which, in my opinion, proves its non-identity with alcohol.

Taking a quantity of this spirit which I had rectified as perfectly as possible, I added to it the same proportion of sulphuric acid that is usually employed to produce sulphuric æther. Instead of obtaining rether, I found a spirit still miscible with water, and burning with a blue flame; its smell being somewhat altered and its specific gravity a little reduced.

The residum in the retort was a black pitchy substance, which became perfectly hard and brittle on cooling.

From what I have stated it is obvious that this fluid is neither alcohol, nor an essential oil, but probably a new variety of æether.

M. Döbereiner appears to suppose that birch-wood especially yields this spirit; but I have found it equally in pyroligneous acid from various other woods.

It appears to me that there is no difficulty in accounting for the formation of this spirit; which, from its greater resemblance to ather than to any other substance, I have called pyroligneous ather. It is well known that no acetic acid exists in wood; yet on exposing it to destructive distillation acetic acid is formed : that is to say, the carbon, hydrogen, and oxygen are liberated from their original combination by the action of the heat; and meeting together under favourable circumstances, they recombine and form acetic acid. The pyroligneous æther is also a ternary compound on the same three simple substances, but in different proportions; and the quantity of it produced will be found to vary according to the circumstances under which the distillation of the wood is conducted. I have constantly 
constantly found in the decomposition of wood, coal, and oil, that both the proportions and qualities of the products are greatly influenced by the temperature, and construction of the apparatus. On decomposing coal, the proportions of the gases, as well as of the ammonia, tar, essential oil, naphthaline, \&c. will greatly depend on these circumstances. On decomposing oil, the products may be diversified by the apparatus employed and by the mode of conducting the operation. I pointed out on a former occasion, that the decomposition of this substance commences at the temperature usually called its boiling point; and I believe the effect called ebullition in this case is merely produced by the extrication of gas; and if fixed oil is thus operated upon, a considerable portion of it is converted into volatile oil. At a higher temperature the carbon, hydrogen, and oxygen of the oil, will either form their full proportion of gas fit for illumination, or acetic acil will be produced, and gas of less illuminating power according to the conditions under which the operation may be conducted.

I have merely sent you these remarks, that the attention of other scientific men who have more leisure may be tempted to pursue a subject which appears to me an interesting one. And I shall be happy if they produce a little inquiry into the nature of the singular fluid which I have described.

Bromlcy, Middlesex, Oct. 18.

I am, gentlemen, yours most truly,

Philip Taylor.

I have sent Mir. Garden, of 372 Oxford-street, some of the pyroligneous rether, that any gentleman wishing to examine it may know where to obtain it.

LIX. O. a Lunar Iris, or Rainbow by Moonlight.

To the Editors of the Philosophical Magazine and Journal.

Gentulemen, - $\mathbf{K}_{\text {Nowing that you are desirous of gratifying }}$ your readers with descriptions of rare meteoric and atmospheric phanomena, I inclose you one for the Philosophical Magazine and Journal, on the Iris Lunaris that appeared here last evening; with a short account of three more that have also been seen here during the last five years.

I am, gentlemen,

Your very obedient servant,

Wilitam Burney.

Last evening at 51 minutes past 6 o'clock, the eastern limb of a lunar iris appeared immediately over Portsmouth Dockyard, and in two minutes afterwards the other limb appeared 